\title{
13. \\ Cancers attributable to solar (ultraviolet) radiation exposure in the UK in 2010
}

\author{
DM Parkin*,I, D Mesher' and P Sasieni'
'Centre for Cancer Prevention, Wolfson Institute of Preventive Medicine, Queen Mary University of London, Charterhouse Square, London ECIM 6BQ, UK \\ British Journal of Cancer (20II) I 05, S66-S69; doi:10.1038/bjc.20II.486 www.bjcancer.com \\ (c) 20II Cancer Research UK
}

The evaluation by IARC (1992) concluded that 'There is sufficient evidence in humans for the carcinogenicity of solar radiation. Solar radiation causes cutaneous malignant melanoma and nonmelanocytic skin cancer. There is limited evidence in humans for the carcinogenicity of exposure to ultraviolet (UV) radiation from sunlamps and sun beds'.

In assessing the quantitative contribution of different exposures to cancer in the UK, we are not concerned with non-melanoma skin cancers. This is because there is no agreed method of enumerating such tumours, which may occur at multiple skin sites throughout life, and, because of their generally trivial nature, are in any case under-enumerated in registration systems.

Evaluation of the proportion of total cases of malignant melanoma that is related to solar (UV) exposure poses many problems. Clearly, the method of estimation based on prevalence of exposure and relative risk is inappropriate, given that there is no 'unexposed' population, and the distribution of relevant types of exposure is unknown.

We have therefore estimated the UV-attributable cases occurring in 2010 as the difference between the number observed and those that would have been expected with a theoretical-minimumrisk exposure distribution, based on historical data from UK. These historical data are the estimated incidence rates for the generation of individuals born in 1903, resident in the South Thames region of England.

\section{METHODS}

Over the last 30 years, the incidence of malignant melanoma has increased more than for any other common cancer in the UK; in males the age-standardised (European standard) rate rose from 2.5 in 1975 to 14.6 in 2007, and it is projected to be 17.0 in 2010; the female age-standardised rate has increased fourfold - from 3.9 to 15.4 - over the same period, with a projected value of 18.0 in 2010 .

The longest series of high-quality incidence data in the UK, with incidence rates from 1960 onwards, is from the South Thames region (Parkin et al, 2005). Figures 1 and 2 show the trends in

*Correspondence: Professor DM Parkin; E-mail: d.m.parkin@qmul.ac.uk incidence between 1960 and 1997 in males and females, respectively.

We fitted an age-cohort model to the South Thames data to reconstruct age-specific incidence rates for age groups without actual observations, and selected the estimated incidence rates in the cohort born in 1903 as our 'reference', with which to calculate expected numbers of cases in 2010, if solar exposure had been as modest as in the 1903 cohort. Age-standardised incidence rates in this generation are some 10-fold lower in males and 6-fold lower in females than those estimated for 2010, but the disparity is considerably greater in the young than in the elderly (Figure 3 ).

\section{RESULTS}

Table 1 shows the projected numbers of cases of melanoma in the UK in 2010 (6096 in men and 6822 in women), and the number expected in the same year if the rates in the 1903 South Thames cohort had been applied. Overall, some $90 \%$ of melanoma cases in men and $82 \%$ in women are estimated to be attributed to 'excess' solar irradiation, although the attributable fractions are very much greater at younger ages. The overall attributable fraction ( $85.9 \%$ of melanoma) is equivalent to $3.5 \%$ of all new cancer cases in the UK in 2010 .

\section{DISCUSSION}

With respect to malignant melanoma the evidence for carcinogenicity of solar radiation is derived from various sources. Descriptive studies (in white populations) show a positive association between incidence of and mortality from melanoma and residence at lower latitudes. Studies of migrants suggest that the risk of melanoma is related to solar radiant exposure at the place of residence in early life. The body-site distribution of melanoma favours sites usually exposed to the sun. Evidence from a large number of case-control studies is generally consistent with positive associations with residence in sunny environments throughout life, in early life and even for short periods in early adult life. Positive associations are generally seen between measurements of cumulative sun damage, expressed biologically as microtopographical changes or history of keratoses or nonmelanocytic skin cancer, and measures of intermittent exposure to 

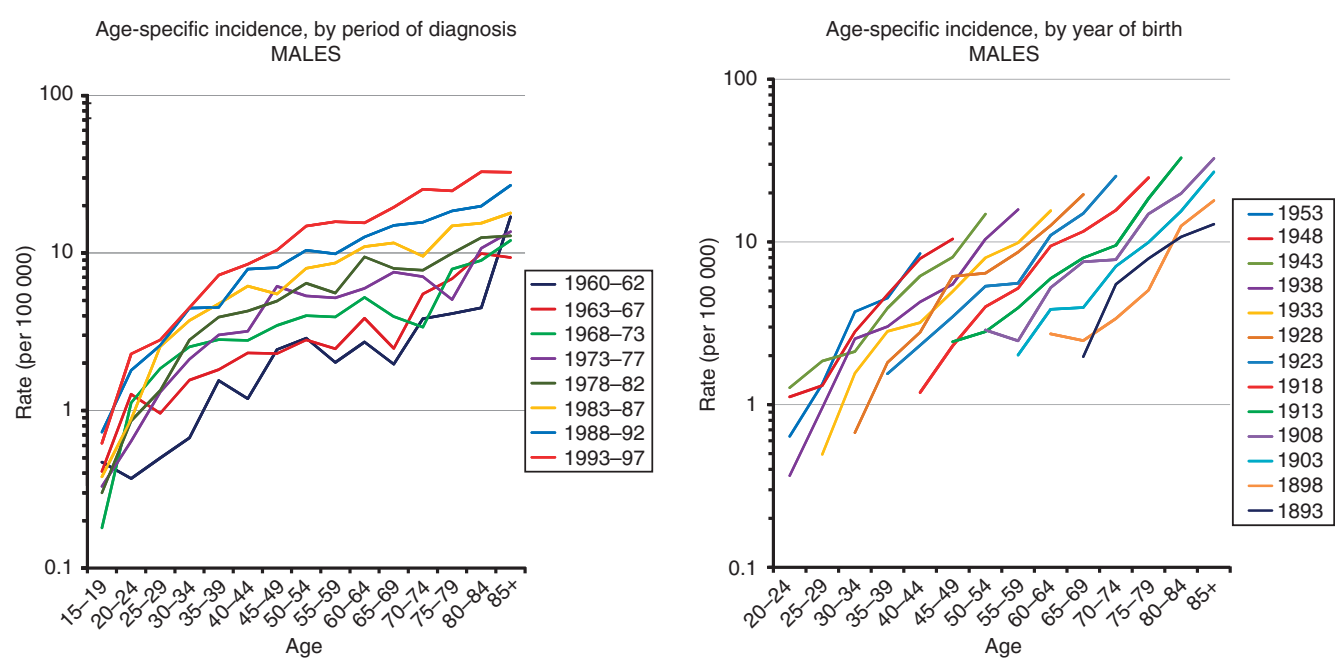

Figure I Trends in incidence of malignant melanoma in the South Thames region, 1960-1997, males.
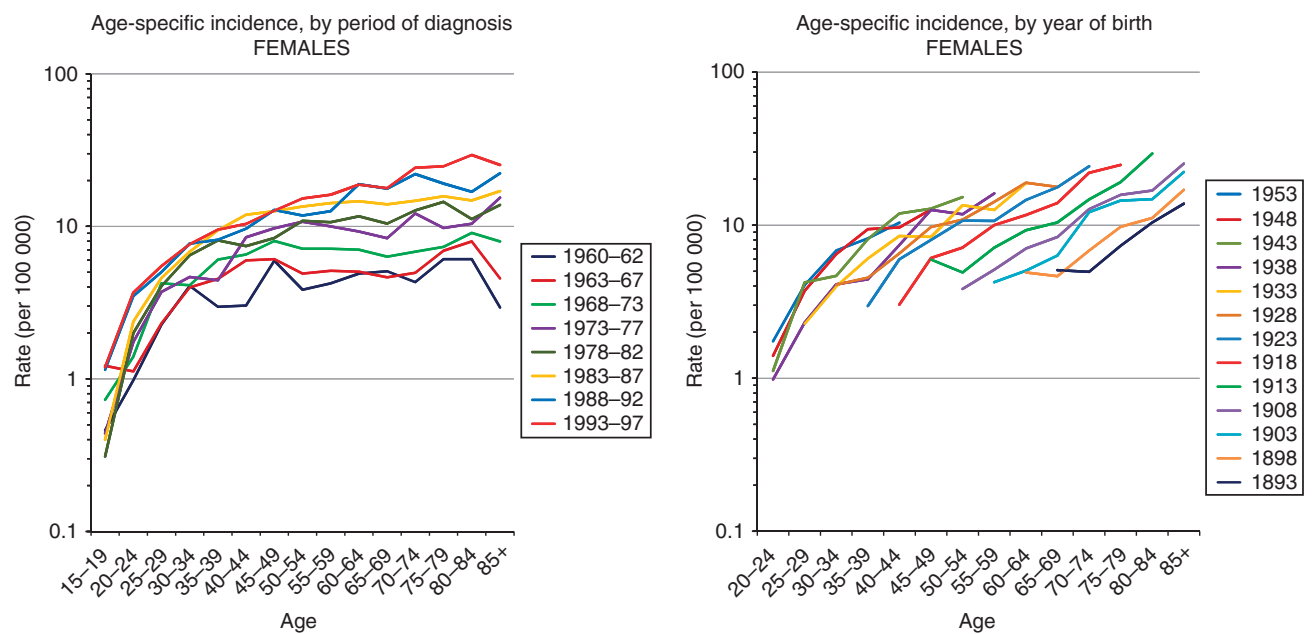

Figure 2 Trends in incidence of malignant melanoma in South Thames region, 1960- 1997, females.

the sun (such as particular sun-intensive activities, outdoor recreation or vacations) and with a history of sunburn. In contrast, chronic exposure, as assessed through occupational exposure, appears to reduce the melanoma risk, an observation consistent with the descriptive epidemiology of the condition, which shows lower risks in groups that work outdoors.

Previous evaluations of the proportion of total cases of malignant melanoma that is related to solar (UV) exposure have also relied on the direct method of estimating attributable risk: the difference between observed incidence in the population and incidence in an 'unexposed' reference group. In a widely quoted study, Armstrong and Kricker (1993) used three different estimates of incidence in 'unexposed' populations to compare with the observed rates in Australia:

- The incidence of melanoma at body sites unexposed to the sun (buttocks and (in women) the scalp, from the Queensland Cancer Registry in 1987; Green et al, 1993).

- The incidence from areas of lower sun exposure in migrants to Australia.

- A comparison of US Whites and US Blacks, in which the incidence in Blacks was taken as the incidence in unexposed Whites.
In the evaluation of avoidable cancers in the Nordic countries, Winther et al (1997) used the crude incidence rates of melanoma at unexposed sites from the above study as the baseline 'unexposed' and estimated attributable fraction in Nordic countries from this study. The IARC's assessment of causes of cancer in France (IARC, 2007) simply took the attributable fraction calculated by Armstrong and Kricker (1993) for Australia as relevant to France in the year 2000. In the evaluation in this section, we chose to use rates from an 'unexposed' reference population that is relevant to UK - the generation born in 1903 in the South Thames region of England.

The pattern of increasing incidence of malignant melanoma in this population over time is a feature of many fair-skinned populations (Lens and Dawes, 2004). In Europe, the increases began first with Scandinavia and the UK and then spread to western, southern and eastern Europe (de Vries et al, 2003). The increase has been mainly for thin melanomas (Lipsker et al, 1999; Mackie et al, 2002). Some of the increase may be due to increased surveillance and early detection, as well as changes in diagnostic criteria, but much of the increase is considered to be real (van der Esch et al, 1991) and linked to changes in sun behaviour 
(Dennis, 1999; de Vries and Coebergh, 2004; de Vries and Coebergh, 2005). Although the trends observed in South Thames could equally well be related to an increase in risk by period of diagnosis, or by birth cohort, we assume that they are in fact due to changes in exposure to solar UV exposure because of altered patterns of behaviour (in choice of clothing and recreational sunshine), producing an increase in incidence that is cohortspecific. This Edwardian generation almost certainly had little bodily exposure to sunlight in their childhood, and even as young adults opportunities for vacations in sunny climates would have been very limited (Figure 4). Nevertheless, exposure was not zero,

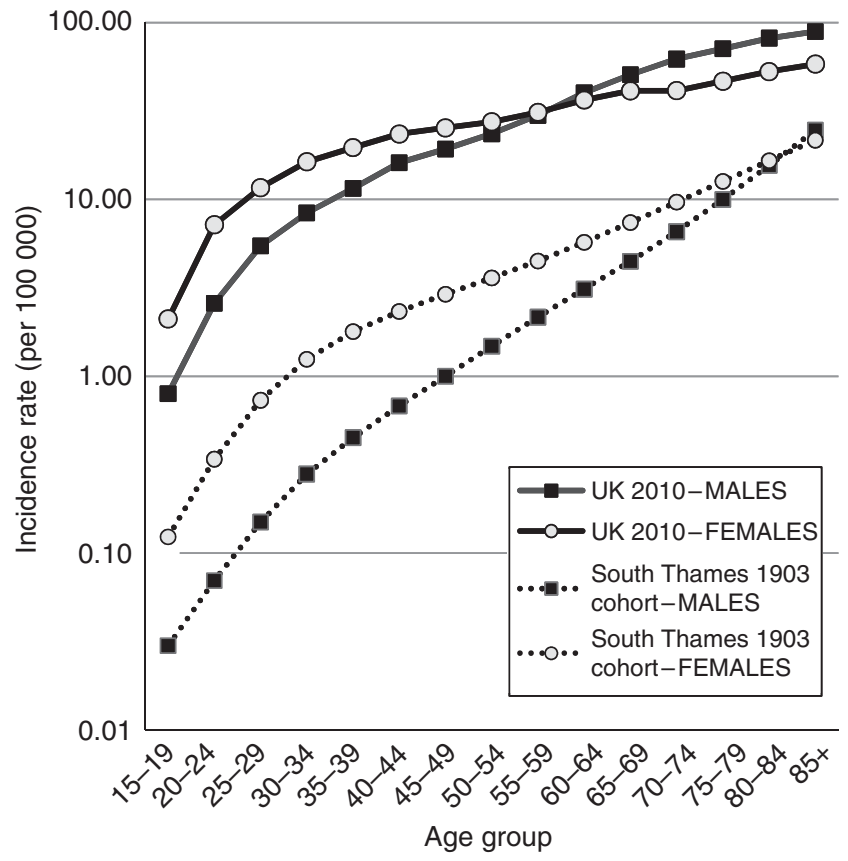

Figure 3 Malignant melanoma: incidence in UK 2010 and South Thames 1903 birth cohort. so that, even at almost $86 \%$, an estimate of PAF will be something of an underestimate.

In a recent update to its evaluation of the carcinogenicity of UV irradiation, IARC reaffirmed the carcinogenicity of solar radiation, but the classification of the use of UV-emitting tanning devices was raised to Group 1, 'carcinogenic to humans' (El Ghissassi et al, 2009). A part of the increase in incidence rates in contemporary UK may well be due to use of sunlamps, but since these devices will almost certainly not have been used by any of the 1903-born

Table I Malignant melanoma cases diagnosed in 2010, estimated to be due to exposure to solar (ultraviolet) radiation

\begin{tabular}{|c|c|c|c|c|c|}
\hline \multirow[b]{2}{*}{$\begin{array}{l}\text { Age } \\
\text { (years) }\end{array}$} & \multicolumn{3}{|c|}{ Malignant melanoma } & \multicolumn{2}{|c|}{ All cancer ${ }^{a}$} \\
\hline & $\begin{array}{l}\text { Relative } \\
\text { risk }\end{array}$ & $\begin{array}{l}\text { Observed } \\
\text { cases }\end{array}$ & $\begin{array}{c}\text { Excess } \\
\text { attributable } \\
\text { cases (PAF) }\end{array}$ & $\begin{array}{c}\text { Observed } \\
\text { cases }\end{array}$ & $\begin{array}{l}\text { Excess } \\
\text { attributable } \\
\text { cases (PAF) }\end{array}$ \\
\hline \multicolumn{6}{|l|}{ Males } \\
\hline$<25$ & 33.50 & 78 & $75.7(97.0)$ & 1853 & 75.7 (4.I) \\
\hline $25-34$ & 32.37 & 284 & $275.2(96.9)$ & 2109 & $275.2(13.0)$ \\
\hline $35-49$ & 21.98 & 1042 & 994.6 (95.4) & 8359 & 994.6 (1 1 . 9 ) \\
\hline $50-64$ & 13.88 & 1717 & |593.3 (92.8) & 37617 & $1593.3(4.2)$ \\
\hline$\geqslant 65$ & 6.81 & 2975 & 2538.4 (85.3) & 108729 & $2538.4(2.3)$ \\
\hline Total & & 6096 & $5477(89.8)$ & 158667 & $5477.2(3.5)$ \\
\hline \multicolumn{6}{|l|}{ Females } \\
\hline$<25$ & 19.31 & 199 & | 88.7 (94.8) & 1646 & $188.7(11.5)$ \\
\hline $25-34$ & 14.18 & 561 & $521.4(92.9)$ & 3284 & $521.4(15.9)$ \\
\hline $35-49$ & 9.72 & $155 \mid$ & $|39| .4(89.7)$ & 16877 & $|39| .4(8.2)$ \\
\hline $50-64$ & 6.89 & 1816 & 1552.4 (85.5) & 41338 & $1552.4(3.8)$ \\
\hline$\geqslant 65$ & 3.69 & 2695 & $1965.6(72.9)$ & 92439 & $1965.6(2.1)$ \\
\hline Total & & 6822 & $5620(82.4)$ & 155584 & $5619.6(3.6)$ \\
\hline \multicolumn{6}{|l|}{ Persons } \\
\hline$<25$ & & 277 & $264(95.4)$ & 3500 & $264(7.6)$ \\
\hline $25-34$ & & 845 & 797 (94.3) & 5393 & 797 (14.8) \\
\hline $35-49$ & & 2593 & $2386(92.0)$ & 25236 & $2386(9.5)$ \\
\hline $50-64$ & & 3533 & $3146(89.0)$ & 78955 & $3146(4.0)$ \\
\hline$\geqslant 65$ & & 5670 & $4504(79.4)$ & 201167 & $4504(2.2)$ \\
\hline Total & & 12918 & | I 097 (85.9) & $31425 \mid$ & 11097 (3.5) \\
\hline
\end{tabular}

Abbreviations: PAF, population-attributable fraction (\%). ${ }^{2}$ Excluding non-melanoma skin cancer.

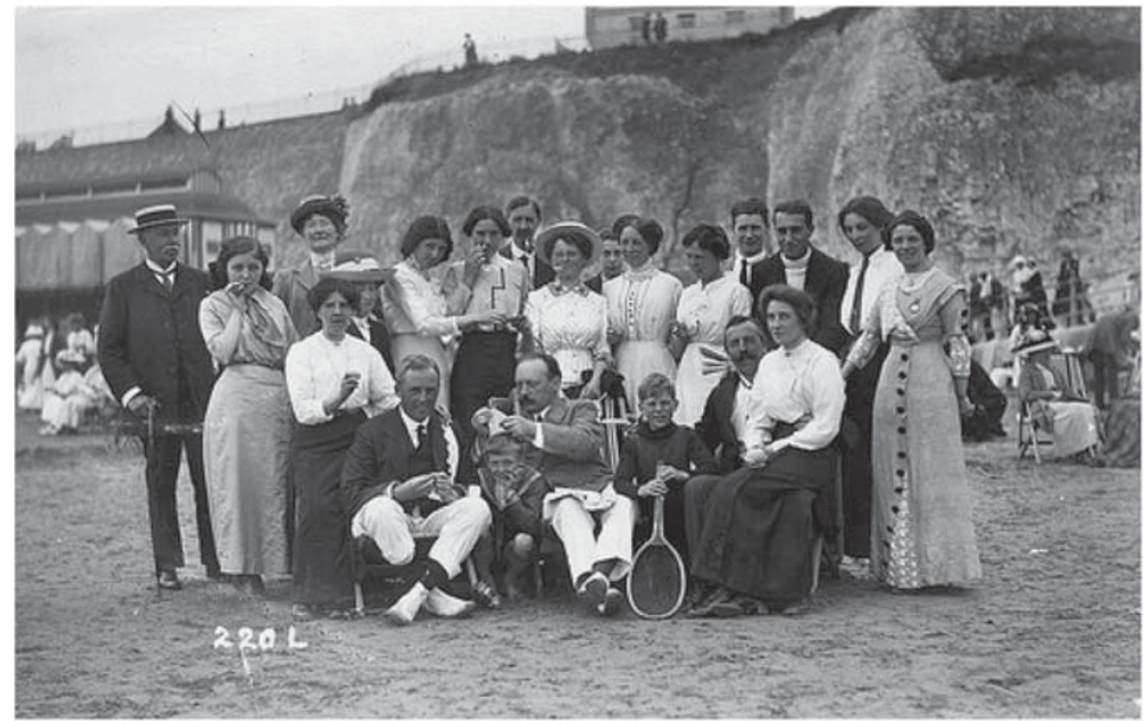

Figure 4 Holiday makers on the beach around |919-1921. 
generation, the estimate of total UV-attributable cancers based on the differences in incidence rates remains a valid approach.

See acknowledgements on page $\mathrm{Si}$.

\section{REFERENCES}

Armstrong BK, Kricker A (1993) How much melanoma is caused by sun exposure? Melanoma Res 3: 395-401

Dennis LK (1999) Analysis of the melanoma epidemic, both apparent and real: data from the 1973 through 1994 surveillance, epidemiology, and end results program registry. Arch Dermatol 135: 275-280

de Vries E, Bray FI, Coebergh JW, Parkin DM (2003) Changing epidemiology of malignant cutaneous melanoma in Europe 1953-1997: rising trends in incidence and mortality but recent stabilizations in Western Europe and decreases in Scandinavia. Int J Cancer 107: $119-126$

de Vries E, Coebergh JW (2004) Cutaneous malignant melanoma in Europe. Eur J Cancer 40: 2355-2366

de Vries E, Coebergh JW (2005) Melanoma incidence has risen in Europe. Br Med J 331: 698

El Ghissassi F, Baan R, Straif K, Grosse Y, Secretan B, Bouvard V, Benbrahim-Tallaa L, Guha N, Freeman C, Galichet L, Cogliano V (2009) WHO International Agency for Research on Cancer Monograph Working Group. A review of human carcinogens - part D: radiation. Lancet Oncol 10: $751-752$

Green A, MacLennan R, Youl P, Martin N (1993) Site distribution of cutaneous melanoma in Queensland. Int J Cancer 53: 232-236

IARC (1992) IARC Monographs on the Evaluation of Carcinogenic Risks to Humans. Vol. 55. Solar and Ultraviolet Radiation. IARC: Lyon

IARC (2007) Attributable causes of cancer in France in the year 2000. IARC Working Group Reports 3.

\section{Conflict of interest}

The authors declare no conflict of interest.

Lens MB, Dawes M (2004) Global perspectives of contemporary epidemiological trends of cutaneous malignant melanoma. Br J Dermatol 150: 179-185

Lipsker DM, Hedelin G, Heid E, Grosshans EM, Cribier BJ (1999) Striking increase of thin melanomas contrasts with stable incidence of thick melanomas. Arch Dermatol 135: $1451-1456$

MacKie RM, Bray CA, Hole DJ, Morris A, Nicolson M, Evans A, Doherty V, Vestey J, Scottish Melanoma Group (2002) Incidence of and survival from malignant melanoma in Scotland: an epidemiological study. Lancet 360: $587-591$

Parkin DM, Whelan S, Ferlay J, Storm H (2005) Cancer Incidence in Five Continents, Vol. I to VIII. IARC Cancer Base No. 7: Lyon

van der Esch EP, Muir CS, Nectux J, Macfarlane G, Maisonneuve P, Bharucha H, Briggs J, Cooke RA, Dempster AG, Essex WB, Hofer PA, Hood AF, Ironside P, Larsen TE, Little H, Philipps R, Pfau RS, Prade M, Pozharisski KM, Rilke F, Schafler K (1991) Temporal change in diagnostic criteria as a cause of the increase of malignant melanoma over time is unlikely. Int J Cancer 47: 483-489

Winther JF, Ulbak K, Dreyer L, Pukkala E, Osterlind (1997) Avoidable cancers in the Nordic countries. Radiation. APMIS Suppl 76: 83-99

cc)(1) (2) This work is licensed under the Creative Commons

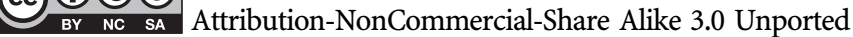
License. To view a copy of this license, visit http://creativecommons. org/licenses/by-nc-sa/3.0/ 